http://jmscr.igmpublication.org/home/ ISSN (e)-2347-176x ISSN (p) 2455-0450 crossref DOI: https://dx.doi.org/10.18535/jmscr/v8i5.23

\title{
Role of CT-Guided Radiofrequency Ablation of Osteoid Osteoma in Long
} Bones

Authors

\author{
Dr Sanjiv Patel ${ }^{1}$, Dr Sapna Patel ${ }^{2}$, Dr Vipul Kamaliya ${ }^{3}$ \\ ${ }^{1}$ Assistant Professor, Department of Radiology, GCRI \\ ${ }^{2}$ Assistant Professor, Department of Radiology, GCRI \\ ${ }^{3} 1^{\text {st }}$ year Resident in Radiology Department, GCRI \\ *Corresponding Author \\ Dr Sanjiv Patel
}

\begin{abstract}
Aims and Objective: To present our experience in treatment of osteoid osteoma of long bones with CTguided radiofrequency ablation (RFA) along with the clinical outcome and long-term success.

Materials and Methodology: 12 patients with osetoid osteoma came to our institute for CT guided RFA have been selected for study.

Result: All procedures were technically successful. No major or immediate complications were observed. Clinical success was achieved in 11 of 12 patients in the first procedure. A second procedure was performed for 1 patient who had recurrent was successfully treated. The overall rate of success was 91.67\%. No complication was observed.

Conclusion: The indications for radiofrequency bone ablation in the case of benign tumours (osteoid osteoma, osteoblastoma) are curative. The long-term outcome of CT-guided RFA of osteoid osteoma is excellent.

Keywords: Ablation, Osteoid osteoma, Computed tomography.
\end{abstract}

\section{Introduction}

Osteoid osteoma is a benign bone tumor predominantly occurring in children and young adults. This tumor accounts for approximately $10 \%$ of all benign bone lesions ${ }^{(1-2)}$.

The most common presentation is bone pain, which usually increases at night and is relieved by nonsteroidal anti-inflammatory drugs or aspirin ${ }^{(3)}$. On examination, there may be focal tenderness but usually no typical signs of inflammation. Pain may be mediated by a possible release of prostaglandin.

On X-ray, osteoid osteoma is seen as dense reactive bone with a radiolucent nidus within which may or may not be easily visualised.
Computed tomography (CT) is the investigation of choice for diagnosis and localization of osteoid osteoma $^{(4)}$.

There are three different treatment options for osteoid osteoma i.e. conservative medical, surgical, and percutaneous intervention. Conservative treatment takes several years for pain relief with an average time of 5-6 years which is not usually accepted by the patients ${ }^{(5)}$. Surgery provides curative relief but significant bone removal is necessary even in small tumors. CT-guided radiofrequency ablation (RFA) appears to be minimally invasive, and cost-effective treatment for osteoid osteoma. 


\section{Aims and Objective}

- To present our experience in treatment of osteoid osteoma of long bones with CTguided radiofrequency ablation (RFA) along with the clinical outcome and longterm success.

\section{Materials \& Methods}

- 12 patients with osetoid osteoma came to our institute for CT guided RFA have been selected for study.

- From May 2018 to January 2020, 12 patients were referred for CT guided RFA of osteoid osteoma (8 males, 4 females). Table 1 summarizes the study population and the clinical, CT, and MRI findings that were used to make the diagnosis

- Patients with symptoms and signs of osteoid osteoma with typical radiological features with visible nidus within the lesion are selected.

- Imaging criteria for diagnosis included radiolucent nidus, adjacent cortical thickening, on both x-ray and CT scan. Surrounding bone marrow edema and Contrast-enhanced/T2-weighted

hyperintense nidus on MRI.
- Before the procedure, complete blood count and coagulation studies were performed. Patients undergoing treatment also required specific imaging criteria, including the documentation of bony sclerosis, cortical thickening, and the presence of a radiolucent nidus on plain film, CT imaging, or both.

- Our institutional review board approved this study. Written consent was taken in all cases.

- All procedures were done under spinal anaesthesia / short GA. Thin section CT (Somatom Emo 6, seimens) scans were obtained to localize the lesion and marked the same.

- An RF electrode was introduced into the nidus. RF electrode was connected to the RF generator, procedure was performed. Procedure took a total of $10-15 \mathrm{~min}$ at a targeted temperature of 90 degrees Celsius during the procedure.

- Post procedural CT was performed to check for immediate post procedural complications such as soft tissue swelling and hematoma.

Table 1 Overview of study population

\begin{tabular}{|c|c|c|}
\hline Patients, & 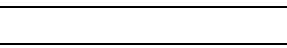 & 12 \\
\hline Age (years) (range) & & 11-38 years \\
\hline \multirow[t]{2}{*}{ Gender, } & Male & 8 \\
\hline & Female & 4 \\
\hline \multirow[t]{5}{*}{ Lesion location } & Femur & 5 \\
\hline & Tibia & 2 \\
\hline & Humerus & 3 \\
\hline & Radius & 1 \\
\hline & Fibula & 1 \\
\hline Making of the diagnoses & Clinical presentation & Children, young adults \\
\hline \multicolumn{3}{|c|}{ Bone pain } \\
\hline \multicolumn{3}{|c|}{ Increases at night } \\
\hline \multicolumn{3}{|c|}{ Relieve by NSAID } \\
\hline \multicolumn{3}{|c|}{ Radiolucent nidus } \\
\hline \multicolumn{3}{|c|}{$+/$ - central calcification } \\
\hline \multicolumn{3}{|c|}{ Adjacent cortical thickening } \\
\hline \multicolumn{3}{|c|}{ Surrounding bone marrow edema } \\
\hline \multicolumn{3}{|r|}{ Contrast-enhanced/T2-weighted hyperintense nidus } \\
\hline \multicolumn{3}{|r|}{ Focal enhancement in the early and late phases } \\
\hline \multicolumn{3}{|r|}{ Double density sign } \\
\hline
\end{tabular}




\section{Results}

The procedure was successful in 11 out of 12 patients $(91.67 \%)$ as evidenced by relief of symptoms within $24 \mathrm{hrs}$. of procedure and no reappearance of symptoms after 1 month follow up.

The follow-up time of the 12 patients was 1 months.

All patients remained symptom-free during the follow-up period, in one of the patient, there was reappearance of symptoms at 3 months after the procedure and recurrence was confirmed on CT scan as appearance of nidus near the same site as previous lesion. The patients were successfully treated with second radiofrequency procedure.

In all the patients, there was no major complication noted in immediate post procedural time. Most frequent complication was pain at the procedural site. Most of the patients were relieved within 24 hrs with IV nonsteroidal anti- inflammatory drugs. One of the patients developed severe pain which was not relieved by IV nonsteroidal anti-inflammatory drugs. The patients were given IV tramadol, and pain got subsequently relieved.

The patients described several significant personal limitations caused by the osteoid osteoma. The highest score was reported regarding the night pain, but other limitations, such as day-time pain, taking medication, limitations regarding daily activities, and effect on performing the job or educational requirements, also had a significant impact. The clinical characteristics are presented in Table 2. A distinct reduction in the VAS scale $(0-10$, with $0=$ no pain/limitation up to $10=$ maximum pain/limitation) was found for all assessed limitation scores. After the RFA, the pain usually resolved within a week, although a delayed resolution was reported in $31 \%$ of the cases.

Table 2 Patient characteristics and treatment course

\begin{tabular}{|c|c|c|c|c|c|}
\hline \multirow[t]{2}{*}{ No. } & \multicolumn{2}{|c|}{ Pre RFA } & \multicolumn{2}{|c|}{ Post RFA } & \multirow[t]{2}{*}{ Recurrence } \\
\hline & VAS score & NSAIDS & VAS sco & NSAIDS & \\
\hline 1 & 3 & yes & 0 & No & No \\
\hline 2 & 2 & yes & 0 & No & No \\
\hline 3 & 8 & yes & 1 & No & No \\
\hline 4 & 1 & yes & 0 & No & No \\
\hline 5 & 10 & yes & 3 & Yes & 3 months later \\
\hline 6 & 5 & yes & 0 & No & No \\
\hline 7 & 2 & yes & 0 & No & No \\
\hline 8 & 2 & yes & 0 & No & No \\
\hline 9 & 9 & yes & 2 & Yes & No \\
\hline 10 & 7 & yes & 0 & No & No \\
\hline 11 & 3 & yes & 0 & No & No \\
\hline 12 & 6 & yes & 0 & No & No \\
\hline
\end{tabular}

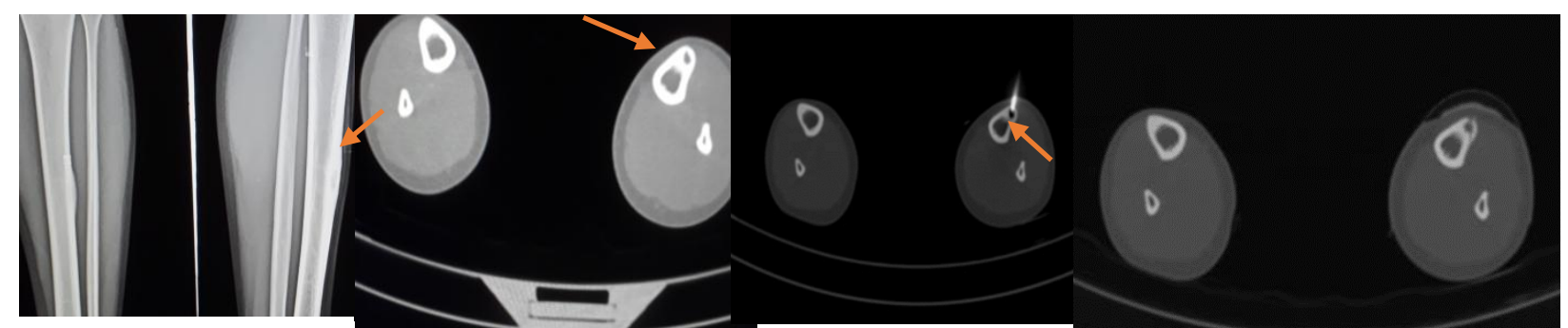

Figure 1 a-d. X-ray / CT morphology and RFA procedure. X-ray (A), shows dense reactive bone with a radiolucent nidus (arrow). Axial CT (B) demonstrates the cortically located nidus leading to a marked surrounding subperiosteal/cortical thickening (arrow). Due to the marked cortical thickening, a power drill was used for bone access, and the nidus was centrally penetrated. The active tip (C) of the ablation electrode was placed centrally into the nidus. CT after the procedure (d) shows the access way but no change in the size or morphology of the nidus itself. 

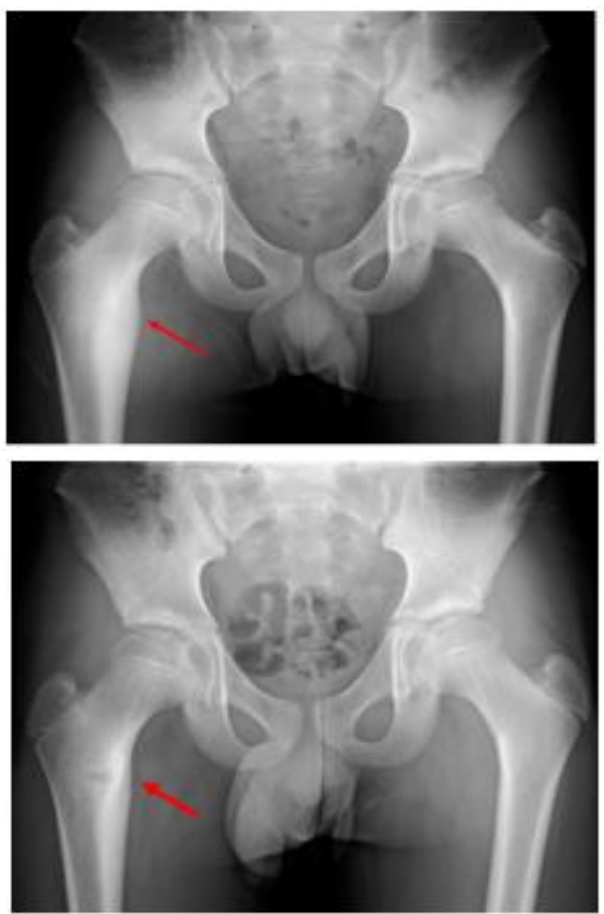

Figure 2 A. 12-year-old male, pre-RFA radiograph A solid cortical thickening and intramedullary sclerotic reaction are visualized in the right femur (arrow). The nidus isn't visible on this plain radiograph. B. Post-RFA radiographThe cortical thickening is improved on post radiograph as compared to the pre radiographs (arrow). Especially, internal protrusion has been reduced. In this case, intramedullary sclerotic reaction has disappeared.
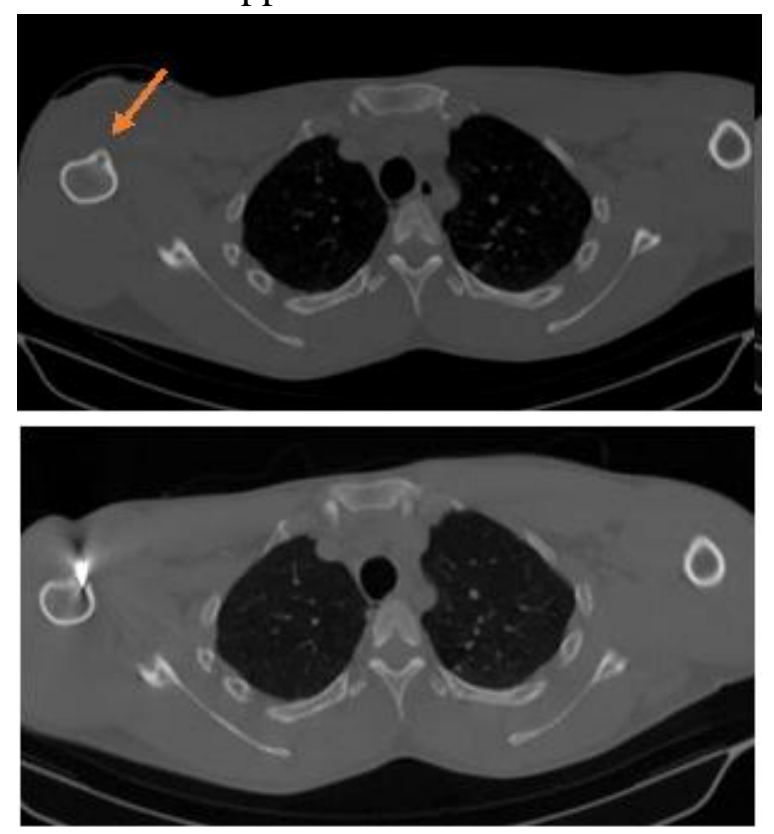

Figure 3. A. Axial CT demonstrates the cortically located nidus in head of right humerus (arrow), leading to a marked surrounding subperiosteal/ cortical thickening. The active tip (B) of the ablation electrode was placed centrally into the nidus.

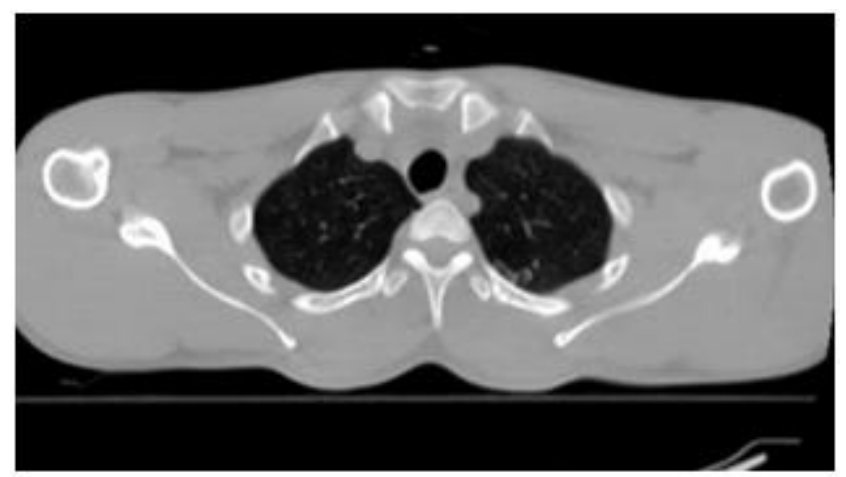

Figure 4 Same patient as in previous casedevelops recurrent lesion after 3 months of RFA

\section{Discussion}

In our study, treatment was successfully performed in $91.67 \%$ of cases. This result is comparable to those reported by many others, ranging from $74 \%-100 \%$. The treatment success percentage is similar to other treatment modalities such as surgical treatment.

The type of probe depends upon the size of lesion to be ablated. For lesions measuring more than 1 $\mathrm{cm}$, two or more electrode positions are required. One of the patient with nidus measuring $13 \mathrm{~mm}$ was successfully treated with 2 probe positions.

Damage to articular cartilage due to thermal effect can occur if the lesions are near to joint cavity.

No major complication occurred in our present study. With proper sterilisation technique and strict temperature control during the procedure, the complications were reduced to minimal. Only troublesome complication was pain after the procedure, which was severe in one of the patient. Use of IV nonsteroidal anti-inflammatory drugs were enough in most of the cases for pain relief. For the patient having severe pain, IV tramadol had to be given but still the pain subsided within $48 \mathrm{hrs}$.

Until now, few complications of RFA for osteoid osteoma have been described in the literature. RFA for spinal and hand lesions are done with extreme precaution to avoid injuries to nerves or spinal cord. A relative contraindication for percutaneous treatment is the presence of a lesion 
near neurological structure (distance $<5 \mathrm{~mm}$ ), due to the risk of damage by hyperthermia-induced cytotoxicity ${ }^{(6-8)}$

There are few limitations of our study. The number of patients in our study were small. Only patients with lesions in long bones were selected which underestimates the number of complications which could occur in lesions at different sites. Histological confirmation was not done in these patients. Diagnosis was based on typical clinical feature and imaging findings.

\section{Conclusion}

The indications for radiofrequency bone ablation in the case of benign tumours (osteoid osteoma, osteoblastoma) are curative.

The long-term outcome of CT-guided RFA of osteoid osteoma is excellent.

There is no correlation of the CT patterns with the clinical outcome. Thus, the treatment decisions should not be solely based on the imaging findings.

Investigators should also be aware of the variety of imaging patterns after RFA.

\section{References}

1. Gangi A, Alizadeh H, Wong L, Buy X, Dietemann JL, Roy C. Osteoid osteoma: percutaneous laser ablation and follow-up in 114 patients. Radiology 2007; 242:293301.

2. Motamedi D, Learch TJ, Ishimitsu DN, et al. Thermal ablation of osteoid steoma: overview and step-by-step guide. Radiographics 2009; 29:2127-2141.

3. Motamedi D, Learch TJ, Ishimitsu DN, Motamedi K, Katz MD, Brien EW, Menendez L. Thermal ablation of osteoid osteoma: overview and step-by-step guide. Radiographics 2009; 29: 2127-2141.

4. Venbrux AC, Montague BJ, Murphy KP, Bobonis LA, Washington SB, Soltes AP,
Frassica FJ. Image-guided percutaneous radiofrequency ablation for osteoid osteomas. J Vasc Interv Radiol 2003; 14: 375-380.

5. Parlier-Cuau C, Champsaur P, Nizard R, Hamze B, Laredo JD. Percutaneous removal of osteoid osteoma. Radiol Clin North Am 1998; 36: 559-566 6 Rosenthal DI, Alexander A.

6. Mylona S, Patsoura S, Galani P, Karapostolakis G, Pomoni A, Thanos L. Osteoid osteomas in common and in technically challenging locations treated with computed tomographyguided percutaneous radiofrequency ablation. Skeletal Radiol 2010; 39: 443-449

7. Martel J, Bueno A, Nieto-Morales ML, Ortiz EJ. Osteoid osteoma of the spine: CT-guided monopolar radiofrequency ablation. Eur J Radiol 2009; 71: 564-569

8. Akhlaghpoor S, Aziz Ahari A, Arjmand Shabestari A, Alinaghizadeh MR. Radiofrequency ablation of osteoid osteoma in atypical locations: a case series. Clin Orthop Relat Res 2010; 468: 1963-1970. 